Association for Information Systems

AIS Electronic Library (AISeL)

Wirtschaftsinformatik 2021 Proceedings

Track 5: Digitization and society - even in times

of Corona

\title{
Understanding pandemic dashboard development: A multi-level analysis of success factors
}

Ludger Pöhler

Universität Osnabrück

Kevin Kus

Universität Osnabrück

Frank Teuteberg

Universität Osnabrück

Follow this and additional works at: https://aisel.aisnet.org/wi2021

Pöhler, Ludger; Kus, Kevin; and Teuteberg, Frank, "Understanding pandemic dashboard development: A multi-level analysis of success factors" (2021). Wirtschaftsinformatik 2021 Proceedings. 4.

https://aisel.aisnet.org/wi2021/VDigitization/Track05/4

This material is brought to you by the Wirtschaftsinformatik at AIS Electronic Library (AISeL). It has been accepted for inclusion in Wirtschaftsinformatik 2021 Proceedings by an authorized administrator of AIS Electronic Library (AISeL). For more information, please contact elibrary@aisnet.org. 


\title{
Understanding pandemic dashboard development: A multi-level analysis of success factors
}

\author{
Ludger Pöhler, Kevin Kus, and Frank Teuteberg \\ Accounting and Information Systems, Osnabrueck University, Osnabrueck, Germany \\ \{ludger.poehler,kevin.kus,frank.teuteberg\}@uni-osnabrueck.de
}

\begin{abstract}
Although dashboards are already widely used in humanitarian crises, various corporate reports and other fields, the specific success factors for the respective application areas often remain unclear. Especially in the current severe corona pandemic, dashboards are crucial to get an overview of the dynamic infection development. This motivated us to investigate how to successfully design dashboards capable of mitigating crises such as serious pandemics. By means of a systematic literature analysis, we identified scientific success factors of crisis and in specific of pandemic dashboards. Further, we assessed currently used corona dashboards and compared them with our success factors of the literature. In this way, we could discover whether corona dashboards are based on previous crisis dashboards and which specific success factors of current corona dashboards can be worked out for future pandemic dashboard development.
\end{abstract}

Keywords: Dashboard, Success Factors, Pandemic, Corona, COVID-19

\section{Introduction}

The COVID-19 pandemic is affecting the whole world. To limit the spread and therefore the negative effects of the virus, effective actions need to be undertaken regionally, nationally and internationally. Next to governmental restrictions for the population like lockdowns or the mandatory wearing of face masks, effective information systems about specific outbreaks in local and national regions can help to raise the common knowledge about infection numbers [1]. One outgrowth of these information systems can be found in dashboards. They can be defined as visual presentation forms built upon purposeful chosen data [2]. Apart from pandemics, dashboards are also used in other forms of humanitarian crises like terrorism [3], wars [4] or environmental catastrophes [5, 6]. With occasionally more than one billion clicks per day [7], the COVID-19 dashboard of Johns Hopkins University (JHU) is one of the most widely recognized at present [8]. Beyond the possible advantages like being able to track the outbreak of diseases in order to answer with purposeful measurements, there are challenges to be overcome and success factors to be considered when developing such a dashboard. 
Current research analyzing dashboards in general and dashboards in pandemic situations in specific focus either on theoretical information from literature or on practical dashboards [9]. Our study, by contrast, analyzes the success factors in the development of pandemic dashboards by considering both publications on previous pandemics and epidemics (pre-corona dashboards) as well as established, real dashboards used for the COVID-19 pandemic (corona dashboards). In addition, aspects from general crisis dashboards are also included in the literature research, which can be transferred to pandemic dashboards. However, these rather are not specific aspects on the detail level, but mainly design and visualization aspects.

This enables us to compare dashboard-literature from the past with the real-world dashboards of the corona crisis by identifying similarities and differences within these two sources. On this base, we derive implications for effective prospective pandemic dashboard development. With our work, we want to answer the following research questions (RQ):

RQ1: Which success factors can be identified in the development of dashboards of past pandemics, epidemics and other general crises situations from literature?

RQ2: What are the specific success factors of dashboards for the corona pandemic?

To achieve that, we structure the article as following: In chapter 2, we present related work dealing with dashboards in the corona crisis. Subsequently, we present the research approach (chapter 3 ). In chapter 4, we analyze the dashboards based on the comparison with identified success factors. Finally, in chapter 5, we critically discuss our results by referring to the research questions and literature. Additionally, we highlight limitations of our work as well as starting points for future research and practical dashboard development.

\section{Related Work}

Since the outbreak of the corona virus, the general population or other specific groups have been informed about the development of the pandemic via dashboards. Numerous scientific studies have already been carried out with different foci to conceptualize, create and evaluate such dashboards of the corona crisis.

For example, Grange et al. [10], Bae et al. [11], Verhagen et al. [12] and Reeves et al. [13] describe the data collection and conceptualization of dashboards in hospitals and clinics in different countries, so that these information are specific and less relevant for the general population. Some guidance is provided on how corona dashboards should be designed at national level. Thus, Berry et al. limited their contribution to the conceptual design of a dashboard for Canada [14]. In this context, a publicly accessible, manually updated dashboard is described. Thereby, their focus is on data quality and resources rather than on design. In addition to the numbers of infected, deceased, recovered and tested persons, also specific characteristics such as location, date and travel history are listed for each case. Marivate et al. focus on similar aspects. Their dashboard concept for South Africa allows to capture overall national and more detailed 
department-specific data at a glance [15]. Other publications rather prioritize the data management behind dashboards and discuss both the necessary multi-resource management [16] and the geoinformatics systems used for location determination [17] in detail. Since it has been discovered that there are extreme deficiencies in the data collection of various known corona dashboards, including the one of World Health Organization (WHO), Ashofteh et al. present an approach for the conceptualization of a dashboard with high data quality [18].

There are also different aspects examined in the publications on dashboards that reflect the global course of the pandemic. For instance, Zavarrone et al. focus on the presentation of socio-economic aspects by using text mining and sentiment analysis to create an overview of social media content in order to identify socially relevant data [19]. Everts et al. describe that corona dashboards also create a feeling of fear in the general population [20]. Approaches and descriptions of how to implement globally accessible dashboards for the entire population are also described. Thus, the basis of the world's most frequently accessed corona dashboard created by the Johns Hopkins University is presented in a short publication by Dong et al. [21]. The basic contents and the structure of the dashboard as well as possible further developments are described. Additional features such as breaking down the information to the local level and comparing pandemic developments in different countries are also offered (c.f. [1], [22]). Tewtia et al. outline how the underlying data can be used to forecast case numbers, which are then compressed and presented in a dashboard [23]. Raghavan et al. are also dedicated to forecasting and its visualization with a focus on Indian population [24].

To the best of our knowledge, in the dynamic development, there is only one publication that compares different worldwide corona dashboards [7]. However, the focus here is strongly on dashboards that use localization technologies such as Global Positioning System (GPS) as well as Artificial Intelligence (AI). Moreover, their investigations are largely limited to Indian dashboards, and the underlying methods are not transparently specified. Thus, a methodological approach should be used to examine the extent to which dashboards in the corona crisis are oriented towards the success factors of dashboards of previous epidemics and pandemics (pre-corona dashboards). In addition, it should be highlighted which further elements in the corona crisis can be identified as success factors for humanitarian crisis dashboards in general and pandemic dashboards in particular.

\section{Research Approach}

In order to fill the research gap and answer our above questions, we adopted a threestep approach. Step 1: By means of a comprehensive literature review according to vom Brocke et al. [25], we systematically identified the success factors of pre-corona dashboards. In the following, we categorized and iteratively determined these by applying a qualitative content analysis according to Mayring [26]. Step 2: Through an extensive Google search, we selected an adequately broad sample of current corona dashboards including national and global dashboards as well as dashboards of 
authorities and public media. Step 3: In this step, we defined the extent to which the previously identified success factors are reflected in the corona dashboards. For this purpose, we compared and evaluated the dashboards with the success factors using a matrix. Thus, through the application of this case study, the theoretical findings from the literature could be compared with the characteristics of real existing dashboards. This allowed us to determine to what extent the success factors are still valid or whether additional elements can be mapped in the corona dashboards. Figure 1 summarizes this procedure.

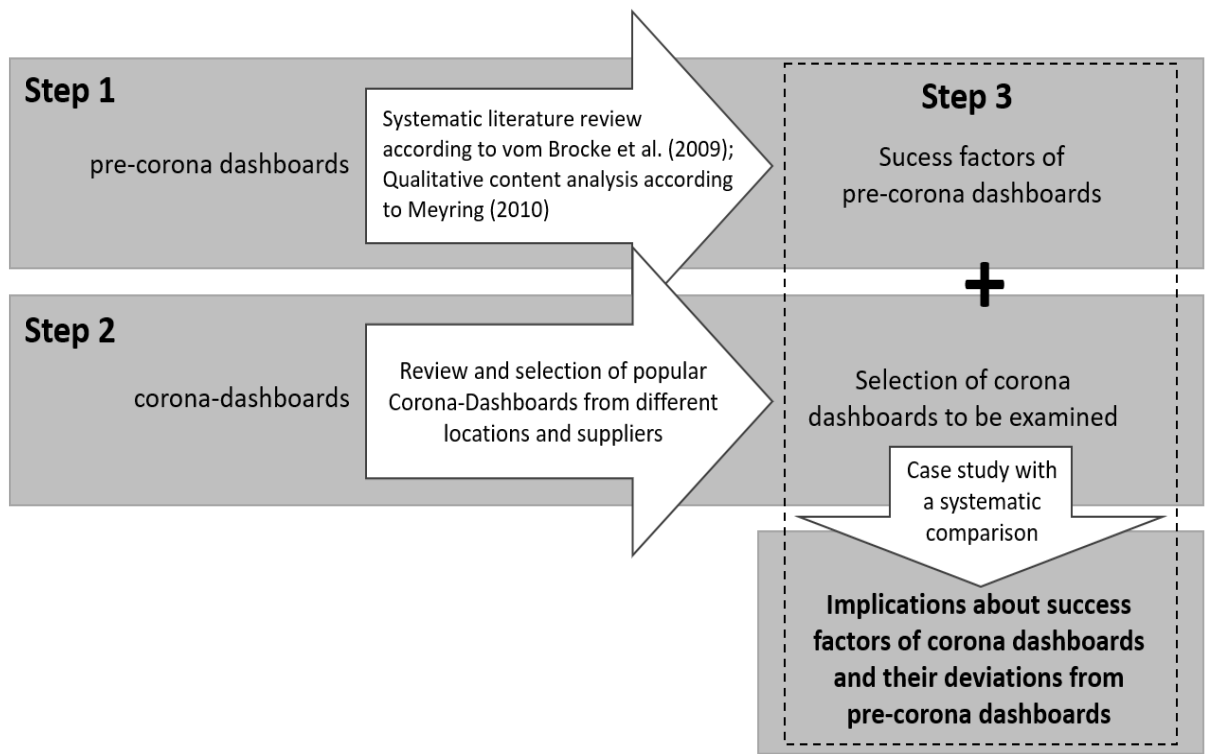

Figure 1. Procedure for identifying sustainable success factors for pandemic dashboards

The success factors of pre-corona dashboards are mainly a consequence of the requirements and design principles of previous epidemics and pandemics. In order to identify the relevant literature for creating dashboards in such humanitarian crisis situations, a complete literature search was conducted according to vom Brocke et al. [25]. He recommends four basic phases in order to obtain the correct and relevant publications on a specific topic. In the first phase, the depth of the literature analysis should be determined by defining the estimated literature volume. Here, vom Brocke et al. follow the taxonomy proposed by Cooper and define six characteristics with two to four categories for each characteristic [27].

The basic goal of the literature analysis was to achieve integration, allowing literature to be compared, summarized and key principles of the dashboard development for epidemics and pandemics to be identified. The focus was to gather previous research outcomes on dashboard applications. The subsequent organization and classification primarily took place on a conceptual basis with reference to the historical development of some principles. When presenting the identified 
contributions, we take a neutral and rational perspective. Further, the results should be relevant for a broad audience, especially for dashboard developers and their clients (practitioners/politicians) as well as for the core target group, the general public. But also, general scholars, who want to make information available to a broad mass in a compressed form, can use the results for future developments. Given the technical progress, we only included sources of the past 15 years and thus chose a representative approach for the coverage of the existing literature. Figure 2 summarizes our procedure with regard to Cooper's taxonomy.

\begin{tabular}{|c|c|c|c|c|c|}
\hline \multicolumn{2}{|c|}{ Characteristic } & \multicolumn{4}{|c|}{ Categories } \\
\hline 1 & goal & integration & \multicolumn{2}{|c|}{ criticism } & central issues \\
\hline 2 & focus & $\begin{array}{l}\text { research } \\
\text { outcomes }\end{array}$ & research methods & theories & applications \\
\hline 3 & organization & historical & \multicolumn{2}{|c|}{ conceptual } & methodological \\
\hline 4 & perspective & \multicolumn{2}{|c|}{ neutral representation } & \multicolumn{2}{|c|}{ espousal of position } \\
\hline 5 & audience & $\begin{array}{l}\text { specialized } \\
\text { scholars }\end{array}$ & general scholars & $\begin{array}{c}\text { practitioners/ } \\
\text { politicians }\end{array}$ & general public \\
\hline 6 & coverage & exhaustive & $\begin{array}{l}\text { exhaustive and } \\
\text { selective }\end{array}$ & representative & central/pivotal \\
\hline
\end{tabular}

Figure 2. Classification of the literature search according to Cooper [27]

In the second phase of step 1 we combined the terms "pandemic", "epidemic", "crisis" or "emergency" with the term "dashboard" in English and German language as well as in singular and plural (search string: (pandemic* OR epidemic* OR cris* OR emergenc*) AND dashboard*). With this search string the literature databases of Scopus, EbscoHost and PubMed were examined in the third phase. We only considered contributions that relate to dashboard structure, design, conception and content in pandemics, epidemics and non-specific crises and address the general population as relevant for our purposes. General visualization and interaction principles in terms of Human-computer interaction (HCI) were not explicitly included. Firstly, including HCI in general would have been too unspecific and secondly, $\mathrm{HCI}$ is implicitly covered by the principles of the specific dashboards.

In the fourth phase, we filtered out duplicates (166 excluded) from the search results (891 articles in total). We then selected relevant articles first by their titles (607 excluded) and subsequently by reading the abstracts (61 excluded) and full texts (40 excluded). This resulted in 17 relevant articles. In addition, we carried out an extensive forward (additional three articles) and backward (additional five articles) search. In total, we considered 25 articles relevant for our study (cf. Figure 3). 


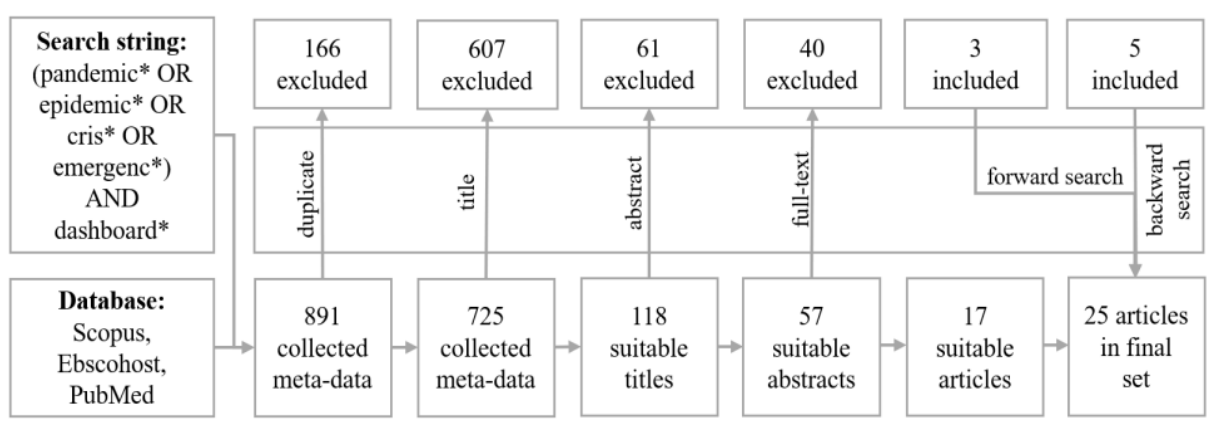

Figure 3. Literature research for pre-corona dashboards (according to Dyba and Dingsoyr [28])

On the basis of these four phases of literature search, we were able to determine the success factors by using a qualitative content analysis according to Mayring [26]. First of all, it was necessary to form categories to classify the success factors. The inductive category development was used for this purpose. When coding the relevant literature sources, a total of 3 main categories (visualization, functionalities, content) with 3 to 11 success factors each could be identified. A comprehensive Google search for relevant dashboards was then carried out in step 2 of our procedure. We paid particular attention to selecting both global and national dashboards from public institutions as well as private media. In step 3, we applied a case study to investigate the extent to which the previously identified success factors were based on the corona dashboards by using a comparison matrix. We then could investigate whether certain success factors are more sustainable and important than others or whether additional success factors of corona dashboards become evident.

\section{$4 \quad$ Results}

\subsection{Literature analysis}

Based on the qualitative content analysis according to Mayring [26], we divided the success factors into three categories, which namely are (1) visualization, (2) functionnality and (3) content. With regard to our literature analysis, we could find more specific success factors within each category.

While content related success factors aim for the task of choosing the right data, visual success factors deal with the challenge of displaying the right data adequately [29]. Additionally, we analyzed factors regarding functionalities, which deal with an interactive and more comfortable user experience with respect to dashboards. In the following, we explain especially those factors within these categories, which were coded most frequently in our content analysis and are described as important in literature. These success factors are displayed in bold in Table 1. 
Table 1. Success factors based on pre-corona dashboards

\begin{tabular}{|c|c|c|c|}
\hline & Success factors & Short description & Reference \\
\hline \multirow{6}{*}{ 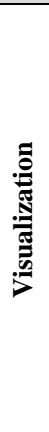 } & Mixed usage & Combination of visualizations and textual elements & {$[30]$} \\
\hline & $\begin{array}{l}\text { Modest visual } \\
\text { elements }\end{array}$ & $\begin{array}{l}\text { Avoidance of non-data visual elements like graphics; map } \\
\text { reduction to borders }\end{array}$ & {$[9,31]$} \\
\hline & Maps & $\begin{array}{l}\text { Information about geographical spread; Awareness of } \\
\text { regional trends }\end{array}$ & {$[30-36]$} \\
\hline & $\begin{array}{l}\text { Ease and } \\
\text { familiarity }\end{array}$ & $\begin{array}{l}\text { Simple visualization interface; Familiar visualizations like } \\
\text { graphs; Visual orientation to interfaces of popular } \\
\text { institutions }\end{array}$ & $\begin{array}{l}{[9,31,35,37-} \\
39]\end{array}$ \\
\hline & Colors usage & Moderate use of colors; Black or gray interface & {$[2,31]$} \\
\hline & $\begin{array}{l}\text { Number of } \\
\text { visual elements }\end{array}$ & $\begin{array}{l}\text { Avoidance of cognitive overload; Limited number of } \\
\text { visual elements }\end{array}$ & {$[31,40,41]$} \\
\hline \multirow{3}{*}{ 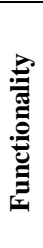 } & $\begin{array}{l}\text { Data sharing } \\
\text { option }\end{array}$ & $\begin{array}{l}\text { Knowledge reuse through data sharing; Teamwork } \\
\text { function; Messaging function }\end{array}$ & {$[37,42,43]$} \\
\hline & Interactivity & $\begin{array}{l}\text { Flexible data filtering; Customization; Drill down } \\
\text { functions; Visual interaction; Comments }\end{array}$ & $\begin{array}{l}{[2,31,34,37-} \\
39,42,44-49]\end{array}$ \\
\hline & $\begin{array}{l}\text { User- } \\
\text { friendliness }\end{array}$ & $\begin{array}{l}\text { Ease of use; Workload reduction; Simple interface; } \\
\text { Intuitive navigation }\end{array}$ & {$[9,31,42,50]$} \\
\hline \multirow{10}{*}{$\stackrel{\vec{\Xi}}{\ddot{\Xi}}$} & $\begin{array}{l}\text { Data source } \\
\text { knowledge }\end{array}$ & Source identification of data used & {$[31]$} \\
\hline & Reliability & $\begin{array}{l}\text { Reliability of used data; Elimination of duplicates and } \\
\text { further errors; Usage of official governmental sources }\end{array}$ & {$[32,38,48]$} \\
\hline & $\begin{array}{l}\text { High-level- } \\
\text { aggregation }\end{array}$ & Data condensing; Data integration & {$[31,48]$} \\
\hline & $\begin{array}{l}\text { Easy knowledge } \\
\text { transfer }\end{array}$ & $\begin{array}{l}\text { Easily understandable information; Only provision of } \\
\text { necessary information to avoid cognitive overload }\end{array}$ & {$[30,34,47]$} \\
\hline & $\begin{array}{l}\text { Several data } \\
\text { sources }\end{array}$ & $\begin{array}{l}\text { Usage of several data sources like social networks, local } \\
\text { databases and remote networks }\end{array}$ & {$[30,32,34]$} \\
\hline & $\begin{array}{l}\text { (Automated) } \\
\text { Data currency }\end{array}$ & $\begin{array}{l}\text { Up-to-date information; Illustration of real time activities } \\
\text { of infectious diseases; Automated update integration }\end{array}$ & $\begin{array}{l}{[31,32,36,38,} \\
39,43]\end{array}$ \\
\hline & $\begin{array}{l}\text { Automated } \\
\text { warnings }\end{array}$ & $\begin{array}{l}\text { Alerts when exceeding thresholds; Furthermore, bright } \\
\text { colors or general highlighting in case of increasing trends }\end{array}$ & {$[2,43,46]$} \\
\hline & $\begin{array}{l}\text { Focus on central } \\
\text { information }\end{array}$ & $\begin{array}{l}\text { Provision of important information to avoid overload and } \\
\text { consequently loss of important information. User's effort } \\
\text { should be reduced both in cognitive and physical way }\end{array}$ & {$[31,41,47]$} \\
\hline & $\begin{array}{l}\text { Mainstream } \\
\text { Usability }\end{array}$ & $\begin{array}{l}\text { Information provision on single screen; Support of correct } \\
\text { data interpretation; Self-explaining dashboard; Minimized } \\
\text { distraction }\end{array}$ & {$[2,31,37,39]$} \\
\hline & Key figures & $\begin{array}{l}\text { Indicators like mortality rate or prevalence rate; Usage of } \\
\text { timelines showing key figures over time periods for } \\
\text { development illustration }\end{array}$ & $\begin{array}{l}{[2,34,35,51,} \\
52]\end{array}$ \\
\hline
\end{tabular}

Content: Dashboards must include reliable data [32, 38, 44, 48]. Reliability needs to be proven either manually or by means of new automated techniques such as supervised learning [44]. Another way of validating a certain quality standard of the data included, is to use official sources like governmental databases [48]. According to the literature, 
the up-to-dateness of the data also constitutes an important factor. It is essential to provide up-to-date information when a user loads the screen [31]. This equally requires that the dashboard needs to be updated constantly, i.e. as soon as new data is available. Updates should be integrated automatically [38]. Apart from that, the data content needs to be easily understandable to its respective users. Provision of only necessary information is essential to avoid overload and loss of important information. To make it understandable to the whole society, information should be displayed on a single screen to reduce navigation [31]. The content of the dashboard should be as selfexplanatory as possible [2]. Reducing distraction by avoiding new processes or required learning is essential [2, 39]. In order to gain complete information and minimize probabilities of errors, multiple data sources should be used. Data sources can be situated in local places and in different social networks [30, 37]. Despite the fact that many articles do not explicitly deal with (infectious) diseases, several articles mention specific ratios explaining the current level of disease distribution. These indicators are number of deaths [51] and number of cases [48, 51, 52], the mortality rate [52], incidence rate $[51,52]$, test numbers $[52]$ as well as prevalence rate $[38,52]$ or the distribution of disease subtypes [38]. Regarding information in visualizations, especially timelines showing cases and rates over time axes are illustrated to show current developments.

Functionalities: Several articles highlight the possibility of flexible data filtering in order to let the user gain more specific data. Exemplarily, users should be able to select specific category groups, data for different time periods or filter data by the type of disease [38]. These filters should be adaptable to the personal needs of the users [2]. Besides, the possibility to select specific geographical characteristics is emphasized [31]. In general, the dashboard needs to be customizable [31]. More concretely, users should be able to choose the style of visual presentation like bar chart, graphs or tables. In order to design an effective dashboard, all relevant information must be made available to all users on one page only, which requires interactive tools such as filters due to the fact that different user groups seek for different information sets. Moreover, navigating through hyperlinks, buttons or going back- and forwards are further ways to interact with the dashboard [42]. Beyond interactivity, user-friendliness was mentioned. Regarding this, the dashboard should reduce the workload for its users [31]. This includes having a simple visualization interface and intuitive, easy navigation methods [32]. Through intuitive use, a cognitive overload is avoided [50]. These aspects are strongly related to a higher ease of use. User-friendliness can also refer to an easy access for all potential users, which includes not only providing an adequate interface for desktop users, but also for mobile devices [30]. Consequently, users can focus on and better understand the content itself without being bound to a specific device.

Visualizations: A map is needed to raise awareness of the general spread of the diseases [31]. GIS-interfaces are considered to be especially important [33]. Maps can display a more detailed view, as users can observe trends within regions [38]. Next to maps in particular, the applied visualization elements should be familiar to users. Those familiar elements like graphs allow rapid customizing [37]. Despite their necessity and benefits, graphical elements should not be used too extensively, but rather rely on the 
paradigm of minimalism or at least on moderate use. Users should not be overwhelmed by unnecessary and distracting information when provided with graphical elements [46]. This implies both to use only a limited number of graphical elements and to illustrate them in a restrained way. Building on this, colors should be used conservatively, which means working with black or gray for most of the interface [31]. Only specific and important information, like urgent alerts, can be marked in bright colors like red to highlight their relevance [31].

\subsection{Dashboard analysis}

In order to compare the above-mentioned success criteria with those of COVID-19 dashboards, an adequate selection of dashboards had to be made first. It was important for us to obtain an overview of the existing dashboards that was as comprehensive as possible. For this purpose, we selected dashboards from general health authorities of governmental organizations (Germany/Robert-Koch-Institute (RKI) [53], USA/Centers for Disease Control and Prevention (CDC) [54], UK [55], India [56], Pakistan [57]), from further public institutions (JHU [7], WHO [58]) as well as dashboards of frequently accessed online newspapers or search engines (New York Times (NYT) [59], Zeit [60], Google [61]). Given that the selected dashboards stem from diverse institutions and mostly focus on different geographical regions, we achieved a higher level of independence between the dashboards. Regarding the granularity level, most of them show more detailed data for their specific geographical areas and thus use different sets of databases. As the dashboard designs differ, we also ensured uniqueness. Figure 4 exemplarily shows the popular JHU dashboard.

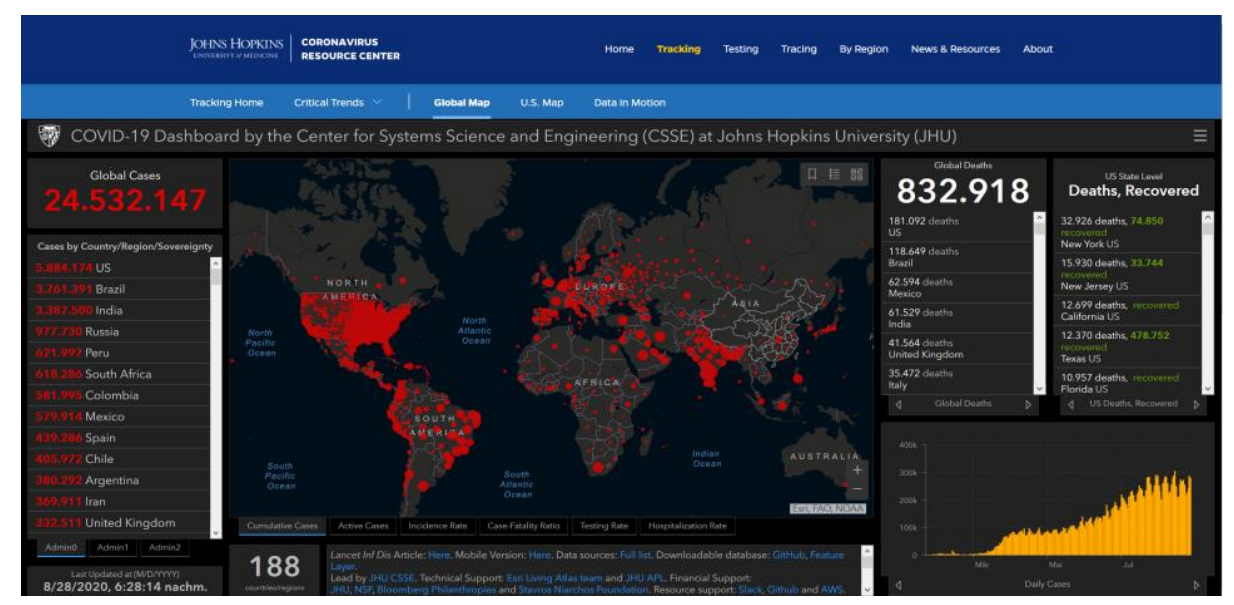

Figure 4. JHU dashboard central screen [7]

The analyzed dashboards serve as a source of information for a large number of citizens during the pandemic. We have included both dashboards that present the pandemic globally and dashboards that focus on a national overview. For the national dashboards, we concentrated on densely populated countries such as India, the USA, Pakistan, 
Germany and the UK. Due to the better analyzability of the data, we limited the presentation to dashboards that are available in German or English. In the following parts, we analyzed these dashboards by comparing them with the previously identified success factors as illustrated in Table 1. The evaluation of practical dashboards is presented in Table 2 and shows to what extent the respective dashboard fulfills the success factors. An " $\mathrm{x}$ " means, that the respective aspect is fully considered. An "(x)" indicates, that the aspect is either partially fulfilled or not directly visible, because it might be on a subpage. Lastly, a "-“"illustrates, that the factor is not included.

Table 2. Comparison of the corona dashboards with the success factors

\begin{tabular}{|c|c|c|c|c|c|c|c|c|c|c|c|}
\hline & Success factor & 刍 & $\stackrel{0}{\gtrless}$ & 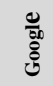 & 西 & 光 & $\underline{\mathbf{Z}}$ & $\stackrel{\varepsilon}{a}$ & : & 己ે & $\frac{\mathbf{z}}{\mathrm{z}}$ \\
\hline \multirow{6}{*}{ 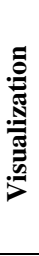 } & Mixed Usage & $\mathrm{x}$ & $\mathrm{x}$ & $\mathrm{x}$ & $\mathrm{x}$ & $\mathrm{x}$ & $\mathrm{x}$ & $\mathrm{x}$ & $\mathrm{x}$ & $\mathrm{x}$ & $\mathrm{x}$ \\
\hline & Modest visual elements & $\mathrm{x}$ & $\mathrm{x}$ & $\mathrm{x}$ & $\mathrm{x}$ & $\mathrm{x}$ & $\mathrm{x}$ & - & $\mathrm{x}$ & $\mathrm{x}$ & $\mathrm{x}$ \\
\hline & Maps & $\mathrm{x}$ & $\mathrm{x}$ & $\mathrm{x}$ & $\mathrm{x}$ & $(\mathrm{x})$ & $\mathrm{x}$ & $\mathrm{x}$ & $\mathrm{x}$ & $\mathrm{x}$ & $\mathrm{x}$ \\
\hline & Ease and familiarity & $\mathrm{x}$ & $\mathrm{x}$ & $\mathrm{x}$ & $\mathrm{x}$ & $\mathrm{x}$ & $\mathrm{x}$ & $\mathrm{x}$ & $\mathrm{x}$ & $\mathrm{x}$ & $\mathrm{x}$ \\
\hline & Colors usage & $\mathrm{x}$ & $(\mathrm{x})$ & $\mathrm{x}$ & $(\mathrm{x})$ & $(\mathrm{x})$ & $(\mathrm{x})$ & - & $\mathrm{x}$ & $(\mathrm{x})$ & $(\mathrm{x})$ \\
\hline & Number of visualizations & 8 & 4 & 6 & 9 & 9 & 4 & 17 & 6 & 6 & 7 \\
\hline \multirow{3}{*}{ 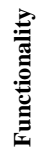 } & Data sharing option & - & - & - & - & - & - & - & $(\mathrm{x})$ & - & - \\
\hline & Interactivity & $\mathrm{x}$ & $\mathrm{x}$ & $(\mathrm{x})$ & $\mathrm{x}$ & $(\mathrm{x})$ & $\mathrm{x}$ & $(\mathrm{x})$ & $(\mathrm{x})$ & $(\mathrm{x})$ & $\mathrm{x}$ \\
\hline & User-friendliness & $\mathrm{x}$ & $\mathrm{x}$ & (x) & $\mathrm{x}$ & $(\mathrm{x})$ & $\mathrm{x}$ & $(\mathrm{x})$ & (x) & (x) & $\mathrm{x}$ \\
\hline \multirow{10}{*}{ 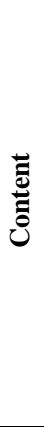 } & Data source knowledge & $\mathrm{x}$ & $\mathrm{x}$ & $(\mathrm{x})$ & $\mathrm{x}$ & $\mathrm{x}$ & $(\mathrm{x})$ & $(\mathrm{x})$ & $\mathrm{x}$ & $\mathrm{x}$ & $\mathrm{x}$ \\
\hline & Reliability & $\mathrm{x}$ & $\mathrm{x}$ & $(\mathrm{x})$ & $\mathrm{x}$ & $\mathrm{x}$ & $(\mathrm{x})$ & $\mathrm{x}$ & $(\mathrm{x})$ & $\mathrm{x}$ & $\mathrm{x}$ \\
\hline & High-level-aggregation & $\mathrm{x}$ & $\mathrm{x}$ & $\mathrm{x}$ & $(\mathrm{x})$ & $(\mathrm{x})$ & $(\mathrm{x})$ & $(\mathrm{x})$ & $(\mathrm{x})$ & $(\mathrm{x})$ & $\mathrm{x}$ \\
\hline & Easy knowledge transfer & $(\mathrm{x})$ & $\mathrm{x}$ & $\mathrm{x}$ & $(\mathrm{x})$ & $(\mathrm{x})$ & $\mathrm{x}$ & $(\mathrm{x})$ & $\mathrm{x}$ & $(\mathrm{x})$ & $\mathrm{x}$ \\
\hline & Several data sources & $\mathrm{x}$ & $\mathrm{x}$ & $(\mathrm{x})$ & $\mathrm{x}$ & $\mathrm{x}$ & $(\mathrm{x})$ & $\mathrm{x}$ & $\mathrm{x}$ & $\mathrm{x}$ & $\mathrm{x}$ \\
\hline & (Automated) Data currency & $\mathrm{x}$ & $\mathrm{x}$ & $\mathrm{x}$ & $\mathrm{x}$ & $\mathrm{x}$ & $\mathrm{x}$ & $\mathrm{x}$ & $\mathrm{x}$ & $(\mathrm{x})$ & $\mathrm{x}$ \\
\hline & Automated warnings & $(\mathrm{x})$ & $(\mathrm{x})$ & - & - & - & - & - & $\mathrm{x}$ & - & - \\
\hline & Focus on central information & $\mathrm{x}$ & $\mathrm{x}$ & $\mathrm{x}$ & $\mathrm{x}$ & $(\mathrm{x})$ & $\mathrm{x}$ & $(\mathrm{x})$ & $\mathrm{x}$ & $(\mathrm{x})$ & $\mathrm{x}$ \\
\hline & Mainstream usability & $\mathrm{x}$ & $\mathrm{x}$ & $\mathrm{x}$ & $(\mathrm{x})$ & $(\mathrm{x})$ & $\mathrm{x}$ & $(\mathrm{x})$ & $\mathrm{x}$ & - & $\mathrm{x}$ \\
\hline & Key figures & $\mathrm{x}$ & $\mathrm{x}$ & $\mathrm{x}$ & $\mathrm{x}$ & $\mathrm{x}$ & $\mathrm{x}$ & $\mathrm{x}$ & $\mathrm{x}$ & $\mathrm{x}$ & $\mathrm{x}$ \\
\hline
\end{tabular}

Content: We identified a wide range of ratios. All dashboards inform about overall cases and overall deaths as well as daily new cases and daily new deaths. In addition to that, overall recovered cases, daily new recovered cases, active cases, overall tests as well as the incidence rates are given in many dashboards. Other ratios were named less frequently. With regard to this, new daily tests or case numbers with regard to age and gender need to be mentioned $[53,57]$. The UK dashboard also provides the current number of COVID-19-patients in hospital and the number of patients needing artificial ventilation [55]. Another indicator is the testing rate [7, 56]. Data-currency of the provided information is important, as well. All analyzed dashboards display the time of the last data update. The majority of dashboards provide data which is not older than 
24 hours. Several dashboards demonstrate data reliability both by informing the public about the exact and extensive data sources used and by including official governmental sources. In most of the dashboards, the content is presented in an easily understandable way. They display the main information on only one screen and provide only four to nine elements on the screen to avoid cognitive overload. The Pakistani dashboard builds an exception as it deploys 17 elements [57]. Most dashboards offer several subpages to provide further data. In order to explain potentially difficult terms, several dashboards provide an information button $[56,60]$.

Comparison with literature: Similar to the findings from the literature, the majority of the analyzed dashboards claims up-to-dateness, the use of several data sources and reliability. Given the severity of the COVID-19 pandemic, this is reasonable, as the potential negative impact of outdated or dubious data is immense and can lead to a significant further spread of the virus. Next to that, we could gain more insights for the used ratios in dashboard design. We know more concretely, which dashboard figures (cases, deaths, increase in cases and deaths, recoveries, active cases etc.) are especially important in pandemics. Contrary to our findings from literature, automated warnings don't play a major role in practical dashboards. This may be reasoned in the fact, that other new technological developments like the "CoronaWarning-App" already focus on such features (like the warning function) more concretely [62].

Functionalities: Interactivity is an essential factor in the analyzed dashboards. Normally, additional information is displayed through simple clicks on links or specific map locations. Filtering is another method to gain more information about chosen time periods, nations or smaller regional areas. The Zeit even allows comment functions [60], which are not available in governmental dashboards. Thus, it can be concluded, that the dashboards provided by media enable more interaction but also are more informal. Data cannot be entered into the dashboards by their users, which is reasonable due to the importance of high data validity. Most of the dashboards achieve userfriendliness through the possibility to use them with mobile devices such as smartphones. FAQs are provided as well [56-58]. Navigating is easy in most dashboards, although it is not always clear which fields can be selected for further filtering. In some cases, user-friendliness was reduced by site loading delays [57], security warnings [57] and the occurrence of downtimes [55]. E-learning possibilities [7], news links [7] or suggested personal behavior [61] are further user-friendly functions.

Comparison with literature: Given the many different interaction tools in the established COVID-19 dashboards, interactivity seems to be even more important than indicated in the literature. This finding can be attributed to the rapidly advancing technical developments and increasing amount of available data, which nowadays enables higher customization. Higher levels of interaction and customization go along with higher levels of general usability. A potential risk, however, is to confuse users by multiple subpages and information overflows.

Visualizations: All dashboards use maps for illustrating the geographical distribution of COVID-19. Maps are kept in a simple way and mostly do not display detailed geographic characteristics like rivers or mountains. Most of the dashboards 
combine the map view with the data itself and provide more aggregated data like the respective country's case numbers, but also more granular regional data within the country. Colors often symbolize good or bad information, as, for example, the Indian dashboard displays the numbers of recovered persons in green color, whereas numbers of deaths are illustrated with black and current case numbers with red color [56]. The Zeit highlights the incidence rates shown as bubbles in red, as soon as the critical threshold is exceeded [60]. However, most dashboards are kept in predominantly moderate colors. While several dashboards are kept in grey, black or white background, some like the Pakistani [57] use colors extensively. Beyond the already mentioned maps, timelines are used often to provide current trends of the disease spread. Some of the dashboards like JHU [7], WHO [58] or RKI [53] provide bar charts. Bubble maps, in which the bubble sizes illustrates the incidence rates, are identified as a new development $[7,58,60]$. As recommended in the literature, most of the dashboards do not display more than nine elements on a single screen.

Comparison with literature: By comparing the analysis results of established dashboards with the literature, it can be stated that the success factors are relatively similar. Identified salience in the analyzed dashboards lies in the outstanding importance of maps to illustrate regional differences of the virus distribution and timelines to illustrate the current trends of COVID-19. Apart from well-known visualizations, bubble maps play an important role. Further, the position of visual elements follows a certain structure in the analyzed dashboards, as the most important numbers like case and death numbers are displayed on the upper left side of the dashboards mostly. This constitutes a new implication not directly mentioned in literature.

\section{Discussion, Limitations and Future Work}

Finally, we examined to what extent our research questions could be answered. First, the success factors of the pre-corona dashboards should be determined. These should be based on dashboards of previous pandemics and epidemics. Higher-level aspects of success should also be examined by including general crisis dashboards. A basis for answering the first research question (RQ1) was built by using the literature and content analysis, from which three main categories could be determined. With regard to the category of visualization, the targeted use of color as well as the use of familiar visualization elements such as bar charts plays a major role [31]. Regarding the dimension of functionality, interactive and user-friendly tools should be built in $[2,9$, 42]. Special emphasis is placed on interactivity, as it gives the user a feeling of selfdetermination and a dynamic way of using the dashboard. With regard to the content dimension and given the severity of the topic (the population's health situation and the danger of deaths), it is deemed especially important to use several reliable data sources [30, 37, 48]. Individual important indicators on communicable diseases such as prevalence and mortality rates have also been identified [52].

We also found answers to our second research question (RQ2). Here it should be examined to which scope the previously identified success factors are reflected in the 
corona dashboards. In the area of visualization, it was recognized that the aspect of maps in the corona dashboards has taken on even a more important role than described in the literature. Furthermore, it was recognized that bubble maps are frequently used in corona dashboards, which allows the user to easily capture how severely a region is affected by the virus. In terms of functionality, the filtering aspect often mentioned in the literature has been further improved in practice. Since higher data transfer rates are possible today, increasingly detailed data can be made available. This allows the user to retrieve an expanding range of regional data. User-friendliness has been frequently mentioned in the literature. By providing the function to use many dashboards as mobile applications, a lot of corona dashboards also meet this requirement. However, at the same time the dashboards lose functionality through the developments of mobile devices. For example, the aspect of warning when thresholds are exceeded is no longer considered to be important. This is due to the fact that efficient corona warning apps take over this function. The user no longer needs to actively obtain the warning and is instead informed via push messages. Considered to be even more important than described in the literature, the aspects "updating" and "reliable data sources" on the content level play an enormous role in the analyzed dashboards. Nearly every dashboard showed the time of the last update which was usually less than 24 hours ago. This is due to the high infectivity with the coronavirus, which can lead to drastic changes in the course of infection within a short time.

These results can be relevant for both dashboard creators and clients, like governments or other official authorities. It can be seen that the success factors of pandemic dashboards have changed only to a small extent over time. Most of the functionality of pre-corona dashboards was also used in corona dashboards. It is important to note that functionalities gain in importance as a result of technical progress (e.g. individualization is better possible due to higher data transfer rates) or may even be outsourced to new applications only focusing on a specific function (warning mechanism is executed by other techniques). This demonstrates that technical progress must always be considered when designing dashboards in pandemics in order to create an information tool adapted to the needs and wishes of the users.

There are some limitations in answering our research questions. Only a limited number of databases was included in the search. Thus, there may be other success factors for pandemic dashboards that could not be identified and considered. Likewise, only a limited number of corona dashboards was included in the analysis, so that success factors of other corona dashboards may have been missed. The evaluation of the dashboards depended on the partly subjective examination of the authors of this article. An evaluation of the dashboards by a larger number of reviewers would provide a more objective result. Since the dashboards do not publish their design principles and templates transparently, it can also not be ruled out that they copied from each other during conception. This could neither be proven nor refuted with the available information.

For future work, the same aspects could be examined with the help of a larger number of databases. Likewise, study participants could be questioned on aspects such as usability and information content of corona dashboards with the help of use cases in order to enable a more objective evaluation of the dashboards. Based on this, a best 
practice for future pandemic dashboards could be developed, which would be available to future governments and dashboard developers as a framework. Mistakes in the development could be avoided and important design aspects could be included. In addition, technical progress in terms of new functionalities must also be considered. Because there is no prediction as to when exactly the next pandemic will come.

\section{References}

1. Barone, S., Chakhunashvili, A., Comelli, A.: Building a statistical surveillance dashboard for COVID-19 infection worldwide. Qual. Eng. 32, 754-763 (2020)

2. Cheng, C.K.Y., Ip, D.K.M., Cowling, B.J., Ho, L.M., Leung, G.M., Lau, E.H.Y.: Digital dashboard design using multiple data streams for disease surveillance with influenza surveillance as an example. J. Med. Internet Res. 13, e85 (2011)

3. Mansoour, S.: Terrorist Watcher: An Interactive Web Based Visual Analytical Tool of Terrorist's Personal Characteristics. Int. J. Data Min. Knowl. Manag. Process. 7, 1-12 (2017)

4. Sloane, E.B., Rosow, E., Adam, J., Shine, D.: JEDI - An executive dashboard and decision support system for lean global military medical resource and logistics management. Annu. Int. Conf. IEEE Eng. Med. Biol. - Proc. 5440-5443 (2006)

5. Tokgoz, B.E., Gheorghe, A. V.: Resilience quantification and its application to a residential building subject to hurricane winds. Int. J. Disaster Risk Sci. 4, 105-114 (2013)

6. Toan, N.T., Tam, N.T.: Early bushfire detection with 3D CNN from streams of satellite images

7. Johns Hopkins Coronavirus Resource Center, https://coronavirus.jhu.edu/map.html (Accessed: 27.08.2020)

8. Devasia, J.T., Lakshminarayanan, S., Kar, S.S.: How Modern Geographical Information Systems Based Mapping and Tracking Can Help to Combat Severe Acute Respiratory Syndrome Coronavirus 2 (SARS-CoV-2) Pandemic around the World and India. Int. J. Heal. Syst. Implement. Res. 4, 30-54 (2020)

9. Tilley, I., Petit, C.: A dashboard for the unexpected: Open data for real-time disaster response. In: Open Cities | Open Data: Collaborative Cities in the Information Era. 265-286. Palgrave Macmillan (2019)

10. Grange, E.S., Neil, E.J., Stoffel, M., Singh, A.P., Tseng, E., Fellner, K.R.B.J., Lynch, J.B., Mathias, P.C., Mauritz-miller, K., Sutton, P.R., Leu, M.G.: Responding to COVID-19 : The UW Medicine Information Technology Services Experience. Appl. Clin. Inform. 11, 265275 (2020)

11. Bae, Y.S., Kim, K.H., Choi, S.W., Ko, T., Jeong, C.W., Cho, B., Kim, M.S., Kang, E..: Information Technology - Based Management of Clinically Healthy COVID-19 Patients : Lessons From a Living and Treatment Support Center Operated by Seoul National University Hospital. J. Med. Internet Res. 22, e19938 (2020)

12. Verhagen, M.D., Brazel, D.M., Dowd, J.B., Kashnitsky, I., Mills, M.C.: Forecasting spatial , socioeconomic and demographic variation in COVID-19 health care demand in England and Wales. BMC Medicine. 18, 1-11 (2020)

13. Reeves, J.J., Hollandsworth, H.M., Torriani, F.J., Taplitz, R., Abeles, S., Tai-Seale, M., Millen, M., Clay, B.J., Longhurst, C.A.: Rapid response to COVID-19: Health informatics support for outbreak management in an academic health system. J. Am. Med. Informatics Assoc. 27, 853-859 (2020) 
14. Berry, I., Soucy, J.-P.R., Tuite, A., Fisman, D.: Open access epidemiologic data and an interactive COVID-19 outbreak in Canada. Can. Med. Assoc. J. 192, E420 (2020).

15. Marivate, V., Combrink, H.M.: A Framework For Sharing Publicly Available Data To Inform The COVID-19 Outbreak in Africa: A South African Case Study. Data Sci. J. 1-7 (2020)

16. Xu, B., Kraemer, M.U.G., Gutierrez, B., Mekaru, S., Sewalk, K., Loskill, A., Wang, L., Cohn, E., Hill, S., Zarebski, A.: Open access epidemiological data from the COVID-19 outbreak. Lancet Infect. Dis. 20, 534 (2020)

17. Boulos, M.N.K., Geraghty, E.M.: Geographical tracking and mapping of coronavirus disease COVID - 19 / severe acute respiratory syndrome coronavirus 2 ( SARS - CoV - 2 ) epidemic and associated events around the world : how 21st century GIS technologies are supporting the global fight against outbreaks and epidemics. Int. J. Health Geogr. 19, 1-12 (2020)

18. Ashofteh, A., Bravo, J.M.: A study on the quality of Novel Coronavirus (COVID-19) official datasets. Stat. J. IAOS. 36, 959-975 (2020)

19. Zavarrone, E., Grassia, M.G., Marino, M., Cataldo, R., Mazza, R., Canestrari, N.: CO.ME.T.A. -- covid-19 media textual analysis. A dashboard for media monitoring. 1-6 (2020)

20. Everts, J.: The dashboard pandemic. Dialogues Hum. Geogr. 10, 260-264 (2020).

21. Dong, E., Du, H., Gardner, L.: An interactive web-based dashboard to track COVID-19 in real time. Lancet Infect. Dis. 20, 533-534 (2020)

22. Wei, X., Wang, M., Kraak, M.-J.: Where we are in fighting against COVID-19. Environment and Planning A: Economy and Space 52, 1483-1486 (2020)

23. Tewtia, H.K., Singh, D.: COVID-19 Insightful Data Visualization and Forecasting Using Elasticsearch. In: Computational Intelligence Methods in COVID-19: Surveillance, Prevention, Prediction and Diagnosis. pp. 191-205. Springer (2020)

24. Raghavan, M., Sridharan, K.S., Mandayam Rangayyan, Y.: Using epidemic simulators for monitoring an ongoing epidemic. Sci. Rep. 10, 1-15 (2020)

25. vom Brocke, J., Simons, A., Niehaves, B. Reimer, K.; Plattfaut, R., Cleven, A.: Reconstructing the giant: On the importance of rigour in documenting the literature search process. ECIS 2009 Proceedings. 2206-2217 (2009)

26. Mayring, P.: Qualitative Inhaltsanalyse. In: Handbuch qualitative Forschung in der Psychologie. pp. 601-613. Springer (2010)

27. Cooper, H.M.: Organizing knowledge syntheses: A taxonomy of literature reviews. Knowl. Soc. 1, 104-126 (1988)

28. Dybå, T., Dingsøyr, T.: Empirical studies of agile software development: A systematic review. Inf. Softw. Technol. 50, 833-859 (2008)

29. Janes, A., Sillitti, A., Succi, G.: Effective dashboard design. Cutter IT Journal. 26, 17-24 (2013)

30. Luchetti, G., Mancini, A., Sturari, M., Frontoni, E., Zingaretti, P.: Whistland: An Augmented Reality Crowd-Mapping System for Civil Protection and Emergency Management. ISPRS Int. J. Geo-Information. 6, 41 (2017)

31. Lechner, B., Fruhling, A.: Towards public health dashboard design guidelines. In: HCI in Business. HCIB 2014. Lecture Notes in Computer Science. pp. 49-59. Springer (2014)

32. Kostkova, P., Garbin, S., Moser, J., Pan, W.: Integration and visualization public health dashboard: The medi+board pilot project. In: Proceedings of the Companion Publication of the 23rd International Conference on World Wide Web. 657-662 (2014) 
33. Rosewell, A., Makita, L., Muscatello, D., John, L.N., Bieb, S., Hutton, R., Ramamurthy, S., Shearman, P.: Health information system strengthening and malaria elimination in Papua New Guinea. Malar. J. 16, 1-10 (2017)

34. Marshall, B.D.L., Yedinak, J.L., Goyer, J., Green, T.C., Koziol, J.A., Alexander-Scott, N.: Development of a Statewide, Publicly Accessible Drug Overdose Surveillance and Information System. American Journal of Public Health. 107, 1760-1764 (2017)

35. Haddawy, P., Wettayakorn, P., Nonthaleerak, B., Yinid, M.S., Wiratsudakul, A., Schö Ningid, J., Laosiritawornid, Y., Balla, K., Euaungkanakul, S., Quengdaeng, P., Choknitipakin, K., Traivijitkhun, S., Erawan, B., Kraisang, T.: Large scale detailed mapping of dengue vector breeding sites using street view images. PLOS Neglected Tropical Diseases. 13, 1-27 (2019)

36. Domdouzis, K., Andrews, S., Gibson, H., Akhgar, B., Hirsch, L.: Service-Oriented Design of a Command and Control Intelligence Dashboard for Crisis Management. 2014 IEEE/ACM 7th International Conference on Utility and Cloud Computing. 702-707 (2014)

37. Nascimento, B.S., Vivacqua, A.S., Borges, M.R.S.: A flexible architecture for selection and visualization of information in emergency situations. In: 2016 IEEE International Conference on Systems, Man, and Cybernetics, SMC 2016 - Conference Proceedings. pp. 3317-3322. Institute of Electrical and Electronics Engineers Inc. (2017)

38. Campbell, T.C., Mistry, Z.S., Gorelick-Feldman, G.N., Hodanics, C.J., Babin, S.M., Lewis, S.H.: Development of the respiratory disease dashboard for the identification of new and emerging respiratory pathogens. Johns Hopkins APL Tech. Dig. 32, 726-734 (2014)

39. Kamadjeu, R., Gathenji, C.: Designing and implementing an electronic dashboard for disease outbreaks response - Case study of the 2013-2014 Somalia Polio outbreak response dashboard. Pan Afr. Med. J. 27, 22 (2017)

40. Nogués, A., Valladares, J.: Business Intelligence Tools for Small Companies: A Guide to Free and Low-Cost solutions. Apress, New York (2017)

41. Zheng, L., Shen, C., Tang, L., Zeng, C., Li, T., Luis, S., Chen, S.-C.: Data Mining Meets the Needs of Disaster Information Management. IEEE Trans. HUMAN-MACHINE Syst. 43, 451-464 (2013)

42. Schöffel, S., Weibell, G., Schwank, J.: A Novel Concept for a Collaborative Dashboarding Framework. In: Advances in Intelligent Systems and Computing. pp. 20-31. Springer, Heidelberg (2018)

43. Francalanci, C., Giacomazzi, P.: Torcia: a decision-support collaborative platform for emergency management, In DATA 2015 (pp. 225-231)

44. Tsou, M.H., Yang, J.A., Han, S., Jung, C. Te, Gawron, J.M., Allen, C., Spitzberg, B.H.: Social Media Analytics and Research Test-bed (SMART Dashboard). In: ACM International Conference Proceeding Series. pp. 1-7. Association for Computing Machinery, New York, USA (2015)

45. Hamid, S., Bell, L., Dueger, E.L.: Digital dashboards as tools for regional influenza monitoring. West. Pacific Surveill. response J. WPSAR. 8, 1-4 (2017).

46. Mordecai, Y., Kantsepolsky, B.: Intelligent Utilization of Dashboards in Emergency Management. Proc. 15th ISCRAM Conf. (2018)

47. Bharosa, N., Janssen, M., Meijer, S., Brave, F.: Designing and evaluating dashboards for multi-agency crisis preparation: A living lab. In: Lecture Notes in Computer Science (including subseries Lecture Notes in Artificial Intelligence and Lecture Notes in Bioinformatics). pp. 180-191. Springer, Berlin, Heidelberg (2010)

48. Jamil, J.M., Shaharanee, I.N.M., Yung, V.C.: An innovative Data mining and dashboard system for monitoring of Malaysian dengue trends. J. Telecommun. Electron. Comput. Eng. $8,9-12(2016)$ 
49. Bhanumurthy, V., Sharma, V.K.: Integration of multiple technologies in web environment for developing an efficient framework for emergency management. In: Springer Series in Geomechanics and Geoengineering. pp. 159-171. Springer Verlag (2019)

50. Limousin, P., Azzabi, R., Bergé, L.P., Dubois, H., Truptil, S., Gall, L. Le: How to build dashboards for collecting and sharing relevant informations to the strategic level of crisis management: An industrial use case. In: 6th International Conference on Information and Communication Technologies for Disaster Management, ICT-DM 2019. Institute of Electrical and Electronics Engineers Inc. (2019)

51. Ziuzianski, P., Furmankiewicz, M., Sołtysik-Piorunkiewicz, A.: E-health artificial intelligence system implementation: case study of knowledge management dashboard of epidemiological data in Poland. Int. J. Biol. Biomed. Eng. 8, 164-171 (2014).

52. Joshi, A., Amadi, C., Katz, B., Kulkarni, S., Nash, D.: A Human-Centered Platform for HIV Infection Reduction in New York: Development and Usage Analysis of the Ending the Epidemic (ETE) Dashboard. JMIR public Heal. Surveill. 3, e95 (2017).

53. Robert-Koch-Institute, https://experience.arcgis.com/experience/478220a4c454480e823b17327b2bf1d4, (Accessed 27.08.2020)

54. Centers for Disease Control and Prevention, https://www.cdc.gov/coronavirus/2019ncov/cases-updates/previouscases.html (Accessed: 27.08.2020)

55. Government of the United Kingdom, https://coronavirus.data.gov.uk/ (Accessed 27.08.2020)

56. Government of India, https://www.covid19india.org/ (Accessed 27.08.2020)

57. Ministry of National Health Services Regulations and Coordination (Pakistan), https://covid.gov.pk/stats/pakistan (Accessed 27.08.2020)

58. World Health Organization, https://covid19.who.int/, (Accessed 2020/08/27)

59. The New York Times, https://www.nytimes.com/interactive/2020/world/coronavirusmaps.html (Accessed 27.08.2020)

60. Zeit Online, https://www.zeit.de/wissen/gesundheit/coronavirus-echtzeit-kartedeutschland-landkreise-infektionen-ausbreitung (Accessed 27.08.2020)

61. Google, https://www.google.com/search?q=coronavirus+dashboard+global\&rlz=1C1CHBF_deDE 860DE860\&sxsrf=ALeKk00U9aio_XVwYKdS1FJgVpQsfS2Dmw:1595849840478\&ei=c LweX6LzHNvBmwWe3an4DQ\&start=0\&sa=N\&ved=2ahUKEwii6-z2q3qAhXb4KYKHZ5uCt84ChDy0wN6BAgLEC8\&biw=1920\&bih=975

(Accessed 27.08.2020)

62. German Government., https://www.bundesregierung.de/breg-de/themen/corona-warnapp/unterstuetzt-uns-im-kampf-gegen-corona-1754756 (Accessed 27.08.2020) 